\title{
Symposiums
}

The Fall Meeting of the Association of Japanese Geographers, 23-24 September 2006

\section{Open Symposium I: Symposium on Food Systems to Networks: Knowledge, Information and Values of Food}

Outlining the Symposium

\author{
TAKAHASHI Makoto \\ Nagoya University \\ ARAKI Hitoshi \\ Yamaguchi University \\ TSUCHIYA Jun \\ Miyagi Gakuin Women's University
}

Japanese society has recently seen growing public concern about the issues of food, in particular quality of foods, brought about by frequent food scares and scandals. These problems obviously arise from the conventional globalized food system, which is characterized by mass production, mass consumption and mass disposal, with an increasing socio-spatial distance being placed between the production and the consumption. In order to overcome them, across Japan, new types of food practice are emerging in farms, communities, markets and households, partly supported by the government, which increasingly takes responsibility for food security, and shifting rural development policy to a postproductivist direction. In this symposium, we concretely discuss what significance these practices have in contemporary society, paying special attention to the notion of 'food network', which is constructed between different sectors by sharing the same knowledge, information and values of food.

Here, the papers brought together present some insights from their empirical studies on various practices in Japan, focusing on the contested process of food quality in locally branded farm products, strategic organic farming for an alternative rural development, the cultivation of a traditional vegetable related to the slow food movement, the roles of children's experiences on farm for environmental education, the local initiatives for the short distance supply of local products, and the food module proposal of supermarket chains to serve consumers, respec- tively. As designated discussants, subsequently, Dr Carolin Funk (Hiroshima University) points to possibilities of and limits to these seemingly alternative food practices, and Professor Harumichi Yamada (Tokyo Keizai University) argues the meaningfulness/meaninglessness of the conceptual framework of 'food network' for analysis. As concluding remarks, it is necessary further to investigate whether the alternative food networks will replace conventional food systems in the Japanese context, as well as to elaborate the conceptual platform itself.

\section{Formation of the Quality in Locally Branded Agricultural Products}

TAKAYANAGI Nagatada

Tokyo University of Agriculture

Food has become one of the key elements for regional economic development in Japan, because the old type strategy such as attracting outside industries or developing tourist resorts cannot work successfully any longer. Since the Regional Trademark Registration was started in April 2006, approximately 70 percent of applications are food-related commodities. Most rural regions nowadays are pitching their specialty products by means of local branding, but some brands are nothing more than toponyms. Branded products need remarkable features that can be distinguished from one another by consumers. In particular, these agricultural products need quality, unique breed variety, and public relations to secure consumers' awareness.

According to the conventions theory, forming the quality of foods involves five criteria: market, industrial, public, domestic, and/or civic convention. Japanese farmers and agricultural cooperatives have been trying to enhance their products in quality: in other words, Fordist agriculture based on mass-production and mass-distribution emphasized the industrial convention. However, 
this is only one aspect for quality foods. No matter how precisely they measure and select shape, color, size, appearance, taste and nutrition using state-of-the-art techniques, consumers do not always have a good impression of the products.

How did branded agricultural products succeed in marketing? This presentation discussed that question through a case study of the Yubari melon. Yubari located in central Hokkaido flourished by coal mining until the 1960s. The Yubari melon, which is one of the most renowned local specialty foods in Japan, was developed in 1960 after the success of crossbreeding. Sugar content is the most important component for favorite fruit taste, but the brix of the Yubari melon is relatively low level. The quality of the Yubari melon is not inherent in the commodity, but is acquired in the relationships among actors. First, organizing small groups encouraged competition with other groups and cooperation with associate members. As a result, farmers strictly observed the grade guideline even during poor harvest. Second, high prices of the Yubari melon attracted news media. Third, the cooperative sincerely answers complaints about bogus melons from consumers, sending new genuine Yubari melons. Accordingly, producers place high value on domestic convention as well as public convention. In Japan, public convention is more significant than in Europe, while civic convention is less.

\section{Regional Significance and Problems Associated with Organic Farming as a Strategy in Production Areas}

MIYACHI Tadayuki Nihon University

Organic farming in Japan had reached a significant turning point. In the 1960 s, only a limited number of farmers and areas were involved in organic farming. However, by the 1990s, the liberalization of agriculture witnessed the third wave and the popularity of organic farming became a widely adopted strategy in the years that followed. These changes occurred in response to a series of food-related problems, which prompted the Ministry of Agriculture, Forestry and Fisheries of Japan to promote sustainable agriculture while setting the standards for the food labeling system and reinforcing the relevant regulations.

There are several advantages associated with adopting organic farming. Firstly, the adverse impact on the farmer's health is markedly decreased. Secondly, through dealing directly with buyers, farmers can form relationships with consumers, which then increase the farmer's motivation to become involved in farm management. Thirdly, organic farming can stabilize selling prices, as organic farmers can enter into agreements with consumers and distributors. Consequently, organic farming has expanded as organic farmers have explored alternate methods of distributing their goods and getting them to market with less competition. So, areas in which it is difficult to improve productivity, such as the hilly and mountainous areas, were particularly interested in adopting organic farming.

On the other hand, there are problems associated with implementing organic farming practices. Firstly, crop yields are unstable. Secondly, working hours tend to increase due to the need for increased weeding. Thirdly, in many cases, the production cost increases. Moreover, it has also been pointed out as not generating sales to the extent that was initially anticipated. In recent years, difficulties associated with selling products have arisen as the organic farming market expands. These difficulties have led to a worsening of various management issues and have made it difficult to organize farmers. This means that the regional significance of organic farming is fluid from a historical perspective as well. In the case of positioning organic farming as a production area strategy in this type of new market environment, new measures should be considered in terms of both production and sales.

\section{Rethinking the Values of Traditional Agricultural Commodities in Japan}

OBARA Norihiro

Ibaraki University

The slow food movement which started in Italy in 1986 to oppose the series of food scares and scandals has been growing as a result of growing demand for the safety of food all over the world. The main philosophy of the slow food movement is founded upon local food consisting of traditional agricultural commodities and 
processed goods. In Japan, the movement has been growing since the 1990s and attracting people to traditional local foods. The author reported such a new movement for traditional agricultural commodities, as an example of arrowhead cultivation in Koshigaya City, Saitama Prefecture.

Arrowheads have been cultivated since the Edo period. We use their roots, which grow like a lotus root in winter, for food. As the growing roots look like birds such as storks and cranes, we have treated them as a bringer of good luck and used for the materials of the traditional Japanese New Year's cuisine. Therefore, arrowheads have been traded at a fair price.

Arrowheads are planted in June and harvested in December. They are shipped only in December. The arrowhead cultivation is characterized by the following two main conditions. First, the producers need to employ additional labors for harvesting in winter, because they cannot use mechanized harvesters for the purpose of keeping good quality. Second, the producers need to make some plots of lowland fields exclusively for the arrowheads far apart from those for paddy rice, because the arrowhead cultivation needs to use irrigation water for longer periods than paddy rice. These characteristics of cultivation have lead to strong networks among producers, and encouraged the organization of producers. At the same time, they have blocked outward development of production centers, keeping them nearby the cities.

Arrowheads have been mainly produced in urban fringes of Saitama and Hiroshima Prefectures. Especially, the arrowheads for demand in Kanto District have mostly been produced in Koshigaya City in Saitama Prefecture. Recently, the changes in people's lifestyles decrease the demand. Consequently, the producers themselves set out the arrowhead processing. Concretely, they make Germanic beer from the arrowhead, based on the strong network of cultivation organization, with the sentiment on disappearing local foods. As a result, now, it is not only the characteristic as a bringer of good luck but also the slow food movement in urban areas which adds value to the arrowhead cultivation in the urban fringe.

\section{Children's Awareness of Relationship between Their Own Town and the Rice Field through the Experience of Rice Planting on the Upstream of Tenpaku River}

OHNISHI Koji

Toyama University

The downstream and midstream areas of Tenpaku River in Aichi Prefecture suffered from a big flood disaster in September 2000. After the experience of this disaster, many citizens' groups are tackling the disaster prevention activities across the Tenpaku River basin. Some groups down stream have tried to make some socio-spatial ties to the upstream communities. In the one of these activities, there is an event of children's experiences of rice transplanting on the upstream farms, which has been held by a citizens' group "Saigai-ni Tsuyoi Machi-dukuri-no Tsudoi (Making a Strong Communities against Disaster)" since 2001.

Children who lived in all the communities on Tenpaku River, ranging from the upstream to the downstream areas, gathered together and experienced rice planting in the spring and harvesting rice in the autumn. At this event, they could exchange their knowledge and information on the river and learn the meanings of varying landscapes along the river.

In the end of the spring event, the owner of the paddy fields mentioned that the rice planting in the upstream area is very important for flood control, because of the paddy fields' function of keeping a lot of water and draining adequately the water to the river. The midstream and downstream areas could be flooded without these rice fields when they get heavy rain.

Even though this event aims for learning the meanings of these relationships between the upstream and downstream areas, most children forget them after the spring event. However, they have chances to remember the meanings when they harvest and eat the rice in the autumn. At that time, they remember their experiences in the paddy field landscape in the spring. Some children are aware of the relationships between the landscapes of the paddy fields and the river. The rice cultivation protects the river running through their neighborhood.

In modern society, the landscape of food production is geographically and socially separated 
from their daily space. But such an environmental education on farm plants in children's minds the awareness that these spaces are certainly connected to each other, and fosters children's understanding of the meanings of landscape and the importance of farming.

\section{Significances of "Chisan-Chisho" (Local Production for Local Consumption) in Vegetable Supply: A Case Study of Toyama Prefecture as a Small and Weak Vegetable Producing Region}

SUKESHIGE Takehisa

Toyama University of International Studies

This report examined the significances of "Chisan-Chisho" (i.e., local production for local consumption) that have been recognized by the vegetable producers, dealers, and consumers in Toyama Prefecture. The vegetable production of Toyama Prefecture is the lowest in Japan, and vegetables for food have been supplied chiefly from other prefectures and other countries. In many cases those vegetables from outside Toyama are not fresh, and therefore it is difficult for consumers to get fresh vegetables. Also, vegetables producers in Toyama have found it hard to sell their fresh vegetables at the same cheaper price as vegetables from outside.

In Toyama Prefecture, the "Chisan-Chisho" approach to vegetable supply has become rather popular since some time around 2002. Many vegetable producers have started selling their products at local stores directly. Especially, the Takaoka-shi agricultural cooperative has become more and more active in such direct sales at supermarkets, in cooperation with wholesalers and dealers. This new practice of the cooperative expanded year by year, and their sales neared the goal of one hundred million yen in the fiscal year 2004. Also, the vegetable production of the whole prefecture recovered from a deficit and reached four billion and three hundred million yen in 2004, some 10 percent of which was occupied by the production obtained from the above-mentioned direct sales.

Through direct sales, vegetable producers, dealers, and consumers in Toyama have realized the significances of "Chisan-chisho" in three ways. First, vegetable producers are able to obtain profits more certainly than by market ship- ments, as they can set up the prices of their products by themselves. Second, supermarket owners can dominate over other dealers in the vegetable division by directly selling fresh vegetables. Third, consumers can get fresh and safe vegetables with ease at nearby supermarkets.

\section{The Network of Stocking Several Spot Commodities in Food Supermarkets}

TSUCHIYA Jun

Miyagi Gakuin Women's University

It is a characteristic that Japanese food supermarkets sell many fresh products and daily commodities. Generally, food supermarkets try to do large quantity sales to make every commodity cheaper. So many economists say that the development of supermarkets result in the emergence of mass consumption society in Japan. In addition, supermarkets introduce several marketing methods to appeal to consumers, who are fickle and always switching stores. Recently, Japanese supermarkets began to introduce several spot sale events positively to increase their repeat users.

To understand the recent trends of food supermarkets, this study pays attention to spot sale events, stocking spot sale commodities and advertising activities for event sales. In particular, this study investigates food networks between supermarkets, distribution businesses and food producers to make clear the role of supermarkets in the mass consumption society. This study presents a case study of Yamazawa Corporation, one of the big food supermarkets in Tohoku region.

Fresh vegetables and fish are very important items in Japanese food culture, and so Japanese food supermarkets try to select better and cheaper foods. Food supermarket buyers collect some information about food producing conditions in every producing district, and new types of development and improvements to stock attractive foods. Buyers also get some information about consuming trends to reduce unpopular food items in their stores. The buyers decide the selling strategies from such information, for example, how many commodities to stock in their stores and for how much their own stores sell several commodities. In addition, food supermarkets deliver handbills inserted in newspapers 
to consumers to inform about their events sales and discount sales. Due to these marketing strategies, food supermarkets can continue to attract consumers.

In this way, large food supermarkets construct food networks positively. The distribution network is physically essential to stock so many foods steadily, because supermarkets can control the distribution time and hold sufficient stocks to sell. The social network between several actors, for example, supermarket buyers, vegetable farmers and farmer cooperatives, is very important to maintain the quality of food in the stores. In addition, the connections between supermarkets and consumers become closer through more frequent event sales and marketing methods.

\section{Symposium II: Regional Transformation after Fiscal Crisis in Korea}

\section{Regional Transformation after Fiscal Crisis in Korea: Opening Address}

KAMIYA Hiroo

Kanazawa University

The development process of Korea is characterized by its intense social conflict due to the higher speed of social transformation. This is because Korea has faced with fierce economic competition with neighboring Japan. As a result, the economic discrepancies between the social classes and regions have emerged as an urgent issue to be dealt with. The monetary crisis of 1997 can be considered as an exposition of the internal contradiction within the Korean society that is concealed within the high economic development. Through the aggressive structural adjustment policy by Korean government to strengthen the international competitiveness of Korean industry, The Korean economy has recovered sooner than other countries. But the restructuring process has advanced more rapidly in the Seoul metropolitan areas, and other local cities and rural areas are left stagnated compared with Seoul.

In this symposium based on the three years research sponsored by JSPS (Japan Society for the Promotion of Science) grants-in-aids, the focus is placed on the current status of local cities and rural areas in Korea. As mentioned above, it is widely acknowledged that the economic crisis has been overcome in Korea in general. But this is only applicable in the Seoul metropolitan areas. Paradoxical coexistence of informal sector and formal sector, pre-modern society and modern society or post-modern society is typically observed in such areas. Each papers in common attempts to shed light on the social structuring in regional revel based on the field work. Through this symposium, we hope to reach the common recognition about the changing local cities and rural areas after the monetary crisis in Korea.

\section{Urban Systems of Korea from the Standpoint of Large Private Firms' Head and Branch Offices: 1985-2002}

ABE Kazutoshi

Aichi University of Education

Through the analysis of the circumstances pertaining to management functions (headquarters and branches of principal corporations), this study aimed to investigate the nature, class, and urban links of the principal cities in Korea. The study was conducted for the years 1985, 1995, and 2002. The leading Korean corporations served as the subjects, and the Annual Corporation Reports served as the source of reference.

The results revealed a marked concentration of the headquarters of these firms in Seoul. In terms of provinces, 75.1 percent of these major firms' headquarters were clustered in the $\mathrm{Ky}$ onggi Province in 2002.

In terms of the number of branch offices, Pusan ranked first followed by Seoul in 1985. However, in 1995 and 2002, Seoul ranked first followed by Pusan. From 1995 to 2002, the number of branch offices in all the major cities except Seoul decreased. This change was greatly influenced by the economic situation in the 1990s.

Next, the author investigated the links among the major cities based on the situation of the branch locations. The results indicated a domi- 